\title{
DE GOTTWALD A FRANCO: EL EXILIO CHECO Y ESLOVACO EN LA ESPAÑA FRANQUISTA ${ }^{1}$
}

\author{
MAROŠ TIMKO \\ Universidad Carolina, Praga
}

\begin{abstract}
Resumen: El estudio está dedicado al asunto del exilio checo y eslovaco en la España de la posguerra. Mediante el análisis del discurso de los principales representantes del exilio se analiza su reflexión sobre la España franquista y sobre la evolución de la situación internacional. Aparte de los estudios de Jozef Cieker, Štefan Glejdura y Bohdan Chudoba publicados en España, el artículo está basado en las memorias de los estudiantes eslovacos, así como en los documentos archivísticos. Con el uso del método comparativo se estudian las relaciones entre los exiliados, interpretándolas en el contexto de la Guerra Fría.
\end{abstract}

Palabras clave: Checoslovaquia, España, exilio, Franco.

Abstract: This study is dedicated to the issue of Czech and Slovak exile in the post-war Spain. Through discourse analysis of the main representatives of exile, it analyses their reflection on Franco's Spain and on the evolution of international situation. Apart from the studies by Jozef Cieker, Štefan Glejdura and Bohdan Chudoba published in Spain, the article is based on the memories of Slovak students, as well as archival documents. With the use of the comparative method, it studies the relations between the exiles, interpreting them in the context of the Cold War. Keywords: Czechoslovakia, Spain, Exile, Franco.

La cuestión de los exiliados checos ${ }^{2}$ y eslovacos sigue siendo uno de los temas poco conocidos no solo dentro de las relaciones entre España y los países detrás del Telón de Acero, sino también dentro de la propia historia de la España franquista. No obstante, las actividades de los estudiantes eslovacos; así como el número relativamente elevado de los exiliados checos en España - 90 personas en el año 1954 (AGA, f. MAE, c. 82/11623, 1.

\footnotetext{
${ }^{1}$ Este texto se ha publicado con el soporte financiero del proyecto de la subvención GA UK no. 788119, con título "Od Gottwalda k Francovi. Český a slovenský povojnový exil vo frankistickom Španielsku" realizado en la Facultad de Filosofía y Letras de la Universidad Carolina. Autor principal del proyecto Maroš Timko, Facultad de Filosofía y Letras de la Universidad Carolina.

${ }^{2}$ En el artículo trabajamos con el término "exilio checo", que debería incluir todos los exiliados procedentes de países checos, que hablaban checo, independientemente de su creencia ideológica. Sin embargo, teniendo en cuenta que los exiliados checos de orientación checoslovaquista dominaron numéricamente dentro del exilio checo (siendo B. Chudoba probablemente el único exiliado checo destacado que rechazaba el concepto de checoslovaquismo), la denominación "exilio/exiliado checo" funciona en este texto como sinónimo del "exilio/exiliado checo de orientación checoslovaquista", salvo indicación diferente. Del mismo modo, el término "exilio/exiliado eslovaco" sirve como sinónimo del "exilio/exiliado separatista eslovaco".
} 
De Gottwald a Franco: el exilio checo y eslovaco en la España franquista

R.4435/21, no. 301/54. Exiliados y residentes checoslovacos en España), comprueban los contactos entre los exiliados de un país con régimen comunista (Checoslovaquia), de un estado inexistente tras las Segunda Guerra Mundial (Eslovaquia) y la España de Franco. Teniendo en cuenta nuevas aproximaciones al estudio de la Guerra Fría (Smith, 2000; Westad, 2007), el enfoque en los exiliados, que salieron de un país con régimen autoritario a otro, puede servir como un punto de referencia para la consiguiente investigación de los contactos mantenidos durante la Guerra Fría, acentuando el papel de los "actores menores" (España, Checoslovaquia) en este conflicto global. A su vez, las reflexiones de la realidad franquista y de la situación internacional sirven como fuente original para el estudio del exilio eslovaco y checo en la España de Franco. En este estudio vamos a procurar mediante el análisis del discurso, "una técnica de análisis potente y precisa [...] [que] puede ser utilizada por metodologías hipotético-deductivas, inductivas y abductivas [...] [y] puede formar parte de estrategias cualitativas y de estrategias cuantitativas" (Sayago, 2014: 3-4).

Las bases para el exilio eslovaco en la España franquista se fundaron ya a finales de la Segunda Guerra Mundial, cuando el embajador del Estado eslovaco Jozef Cieker decidió, en contraste con las instrucciones oficiales del gobierno checoslovaco, no volver a la restaurada República Checoslovaca y quedarse en Madrid. Hay que mencionar que Cieker se adhirió, junto con el resto de la legación eslovaca en Madrid, al servicio del MAE checoslovaco ya el día 10.4.1945, mediante el diplomático Zdeněk Formánek ${ }^{3}$ (AMZV, f. TO - T: España 1945-54, c. 1, carp. 057/151, no. 43779/V-1/48. Nota de J. Cieker). En septiembre de este año Cieker escribió a la embajada checoslovaca en París sobre la emisión de los pasaportes para la legación eslovaca, que se recibieron, junto con el visado de tránsito francés, en enero de 1946. Sin embargo, los diplomáticos eslovacos pidieron la prolongación del visado para "no viajar a lo desconocido" y requirieron el derecho de poder viajar con los pasaportes diplomáticos (AMZV, f. Expedientes personales, carp. Dr. Cieker Jozef, no. 25/res./46). En uno de sus informes Formánek comunica que "todo lo necesario para el viaje de los funcionarios de la antigua legación eslovaca (a Checoslovaquia - nota del autor) ha sido arreglado" y que los diplomáticos eslovacos declaran que su viaje se efectuará hasta final de enero (AMZV, f. Expedientes personales, carp. Dr. Cieker Jozef, no. 143/46). Sabemos que al menos Cieker y su familia realmente salieron de España, sin embargo, de París volvieron a Madrid (Bartlová, 2000: 68). La razón de este regreso fue probablemente la entrevista entre el diplomático eslovaco y Formánek, que le informó de que con su regreso a Checoslovaquia venía vinculada la amenaza del procesamiento contra él (Vurm, 2007: 20). En este caso Formánek tuvo razón, ya que Cieker fue condenado in absentia a la privación de libertad durante cuatro años y a la confiscación de un cuarto de su

${ }^{3}$ Zdeněk Formánek (1889-1962) ejerció la función del encargado de negocios checoslovacos ya durante la Guerra Civil. Como representante semioficial del gobierno checoslovaco se quedó en España hasta 1946, cuando se trasladó a la sección legal del MAE en Praga. Tras el golpe comunista, se exilió en París en abril de 1948, participó en las actividades del exilio checoslovaco y al regresar a Madrid asumió el cargo de representante de los intereses de Checoslovaquia en España. 
propiedad, siendo sus delitos la traición nacional y el colaboracionismo (AMZV, f. Expedientes personales, carp. Dr. Cieker Jozef, no. 391/48).

Si el primer grupo de exiliados se formó alrededor del personal de la legación eslovaca en Madrid y consistió sobre todo en los estudiantes eslovacos de orientación separatista que huyeron de Eslovaquia ya desde 1945, el segundo y más numeroso grupo provino de Checoslovaquia y fue principalmente el resultado de la persecución comunista después de 1948. Este grupo se basó en los emigrantes de Países checos, de orientación checoslovaquista, encabezados por Formánek. Los diplomáticos eslovacos vivían en España, una vez finalizada la guerra, gracias al fondo de reserva de la legación y hasta diciembre de 1945 recibían el mismo sueldo que durante el funcionamiento de la misión diplomática en abril de 1945. Sin embargo, hay que añadir que Cieker entregó a Formánek el día 14 de enero de 1946 el archivo, el inventario, la cuenta final y la existencia en caja de la antigua legación eslovaca (AMZV, f. TO - T: España 1945-54, c. 1, carp. 057/151, no. 43779/V-1/48. Nota del MAE en Praga para el Comisionado de Finanzas en Bratislava). No obstante, al regresar de Francia a España, Cieker, así como el resto de la legación eslovaca, tuvo que buscar otras maneras de ganarse la vida. En este extremo, la decisión de quedarse en la España franquista resultó ser afortunada.

La situación internacional posbélica -la aparición del sistema bipolar-, influyó obviamente en la política exterior de España, que buscaba maneras de salida de su aislamiento internacional, sobre todo cambiando la apariencia del régimen. Como alega Eiroa (2005: 262), las medidas adoptadas por el gobierno español frente a la nueva situación incluyeron también "la catolicidad, el consiguiente estrechamiento de relaciones con el Vaticano y el despliegue propagandístico de su anticomunismo [...]". Con estas medidas está conectada la colaboración de la España franquista con Pax Romana, una organización católica internacional, siendo fruto de esta cooperación la creación de la Obra Católica de Asistencia Universitaria (OCAU) en octubre de 1946. Esta Asistencia a los estudiantes universitarios provenientes de los países comunistas se basó en el otorgamiento de becas en España y culminó en diciembre de 1946 con la fundación del Colegio Mayor Santiago Apóstol (CMSA) en Madrid (Eiroa, 2018: 9). A pesar de que los primeros estudiantes acogidos por la OCAU llegaron a España ya en diciembre de 1946, los primeros estudiantes eslovacos salieron a Barcelona desde Génova el día 23 de diciembre de 1947 y este grupo consistió en Eduard Moščovič, Viliam Koňa, František Chajma y Jozef Kolmajer ${ }^{4}$ (ABS, f. SÚ MV/2M, sign. 12824, no. 03214/48). Como recuerda el último, durante la primavera de 1947 los estudiantes eslovacos, que huyeron a Roma ante el Ejército Rojo, recibieron un mensaje de Cieker

${ }^{4}$ Jozef Kolmajer (1922-2008) alega en sus memorias (1998b: 279) que en abril de 1945 marcharon de Eslovaquia ante el Ejército Rojo unos 4000 exiliados eslovacos con "el bordón del peregrino". Cabe añadir que Kolmajer fue condenado en Checoslovaquia en 1947 in absentia a 30 años de prisión a causa de la colaboración con el Sicherbeitsdienst en la detención de los antifascistas y los judíos en el territorio eslovaco durante la guerra (ABS, f. SÚ MV, sign. Z-10651-14, 7-8). 
diciendo que en Madrid se abrió el CMSA y que se habían ofrecido becas para cuatro estudiantes eslovacos (Kolmajer, 1998b: 285). Kolmajer añade (1998b: 286) que tras su llegada a Madrid, los exiliados se alojaban en el CMSA, donde vivían estudiantes de 16 países comunistas. El número total de estudiantes eslovacos en el CMSA hasta su cierre en 1969 fue 18, siendo el problema inicial de los recién llegados el desconocimiento del español (Vontorčík, 2013: 27). La cuestión crucial y una de las causas de la clausura del colegio fue su financiación, un hecho que se reflejó también en la alimentación de los estudiantes: "las raciones eran pequeñas... el hambre fue el símbolo de una buena salud" y además, "las posibilidades de empleo eran muy escasas" (Belák, 1999: 37-38; 74).

El cargo del director del CMSA fue, a partir de febrero de 1948, ejercido por Cieker. Este hecho influyó de manera positiva en la cantidad de estudiantes eslovacos acogidos por la OCAU que vivían en el CMSA. Su número en la primera mitad de los años 50 tuvo una tendencia creciente: de 7 eslovacos en el año académico 1949-50 a 12 eslovacos en el curso 1954-55. Por otro lado, el número de estudiantes checos decrecía de tal manera, que ya en el curso 1954-55 no había ningún estudiante checo (Eiroa, 2005: 279). Parece que la razón principal de este decrecimiento fue el ejercicio del cargo del director por Cieker, que fue reiteradamente criticado por su orientación separatista, el rechazo de la idea del checoslovaquismo y la preferencia de los estudiantes eslovacos (ibídem: 293). El estudiante checo en el CMSA Antonín Blaha en una carta dirigida al presidente de la OCAU acusó a Cieker de discriminación, falta de sentido de objetividad y de la creación de la base del movimiento eslovaco separatista en Madrid y alegó que sin la ayuda de Formánek, no se habría admitido a ningún estudiante checo en el colegio (AGA, f. MAE, c. 82/11623, l. R.4435/21, no. 301/54. Carta de A. Blaha a José M. Otero Navascués). Hubo conflictos también entre Cieker y Formánek, este acusó a Cieker de ser "agente de Alemania nazi” (AGA, f. MAE, c. 82/9309, 1. R.3358/18. Carta de Z. Formánek a Mariano de Iturralde). A pesar del anticomunismo de los dos diplomáticos, en sus relaciones dominaron la antipatía personal y la contradicción de sus acreditaciones: los dos representaron a un país, que no había sido reconocido por el otro.

Jozef Cieker, aparte de ser Director del CMSA, el Vicepresidente del Consejo Nacional Eslovaco en el exilio y el representante de los intereses eslovacos en España, fue también autor de decenas de ensayos y estudios históricos. Sus artículos se publicaron en el boletín del CMSA Nosotros, así como en las revistas publicadas por el Centro de Estudios Orientales (Oriente, Oriente Europeo, Re-Unión) y en las revistas del exilio eslovaco (Slovák v Amerike, Slovakia). La cuestión eslovaca viene acentuada en casi todos los estudios publicados por Cieker en España en los años 1950 y 1960. En el artículo "La entrada de los eslovacos en la comunidad cristiana" se describe la historia medieval del territorio de la actual Eslovaquia con un enfoque en la cristianización de las "tierras eslovacas" mediante los apóstoles Cirilo y Metodio. Alega que los eslovacos fueron "los primeros eslavos en la Europa central que sentaron bases para un Estado [...] En la lucha entre dos influencias, bizantina y occidental, tomaron la orientación occidental" (Cieker, 1951: 65). El artículo termina con una afirmación, que la actual 
Eslovaquia y sus habitantes son los herederos directos de la magnitud política y espiritual de Gran Moravia - "Estado eslovaco del s. IX", quedando su base étnica inalterada (Cieker, 1951: 74). Naturalmente, es muy problemático denominar a Gran Moravia como un "estado eslovaco" por la carencia de los documentos acerca de su composición étnica. No obstante, es bien comprensible la acentuación del elemento eslovaco como cristiano con una orientación occidental ya desde el s. IX, teniendo en cuenta la publicación del artículo durante la Guerra Fría y la búsqueda de ayuda a favor de la independencia eslovaca mediante el anti-orientalismo (anticomunismo) y el catolicismo español.

Su siguiente estudio, denominado "La lucha por el espacio centroeuropeo" se publicó en cuatro partes en la revista Oriente entre los años 1952-53. Cieker aquí analiza la situación en la Europa Central sobre todo en la primera mitad del s. XX con un enfoque en el problema checo-eslovaco. No sorprende que su interpretación de la Primera República Checoslovaca, así como del sistema de Versalles, basado en los estados multinacionales en Europa Central/Oriental, es crítica. El autor describe Europa Central como el campo de batalla entre la influencia francesa y alemana; a su vez considera los problemas nacionales internos (la opresión de los eslovacos) como la razón principal de la desintegración de Checoslovaquia, calificando el papel de la influencia alemana y la traición de los aliados occidentales como una explicación errónea, como un falso mito (Cieker, 1952a: 154-155). Checoslovaquia era, según su explicación, un estado en el que el poder se concentraba exclusivamente en las manos de los checos, mientras que los eslovacos, en el momento de la crisis (1938), no estuvieron dispuestos a defender este estado y tan pronto como "tuvieron la oportunidad de decidir sobre sí mismos, proclamaron su propia independencia nacional” (Cieker, 1952b: 215). En este sentido, no sorprende la justificación de la política exterior de los "pueblos" de la Europa Central, que por un lado aceptaron la colaboración económica y política con la Alemania nazi, pero rechazaron su ideología nacional-socialista (ibídem: 225). Cieker repetidamente critica a Edvard Beneš, que viene descrito como el máximo responsable de los fracasos de la política interior y exterior checoslovaca y como la persona que "dejó abiertas las puertas a las aspiraciones indefinidas de los húngaros” (Cieker, 1953: 289), lo que tuvo como consecuencia la cesión de la parte meridional de Eslovaquia como el resultado del arbitraje de Viena en noviembre de 1938. Obviamente, las exigencias húngaras frente a Eslovaquia vienen también criticadas por parte de Cieker (ibídem: 289290). El autor procede al asunto de la proclamación de la independencia eslovaca en marzo de 1939, siendo esta "una necesidad histórica y la realización suprema de la voluntad eslovaca [...] [y] una necesidad derivada de los derechos soberanos del pueblo eslovaco y de las circunstancias políticas en la Europa Central"' (Cieker, 1954: 171). En su análisis de la situación centroeuropea, Cieker llega hasta el estallido de la Segunda Guerra Mundial y al subsecuente reparto de Polonia con el que presuntamente se rompió el equilibrio centroeuropeo y desapareció la barrera natural entre Oriente y Occidente (ibídem: 182-184). 
De Gottwald a Franco: el exilio checo y eslovaco en la España franquista

Ahora bien, teniendo en cuenta la orientación política de Cieker, es bien comprensible su crítica hacia Checoslovaquia y sus representantes, sobre todo si sabemos que Formánek, su rival en España, fue concebido por los separatistas eslovacos como el "hombre de Beneš". Teniendo en cuenta su acreditación, también se puede comprender su defensa al Estado eslovaco y a la legitimidad de sus representantes. Sin embargo, es difícil de precisar la razón de su interpretación sobre la situación de estados centroeuropeos en los años 1938-39 y del papel clave que desempeñó en su ruptura el Tercer Reich. Este viene disminuido al omitirse los aspectos negativos de la política nazi, a pesar de que este ensayo se publicó ya en los años 50. La disminución de la culpa alemana en la destrucción de Checoslovaquia debería servir, más probablemente, para subrayar el papel eslovaco en su ruptura. Por otro lado, la concepción de la Europa Central como la barrera entre el Este y el Oeste debería funcionar naturalmente como una prueba de la cercanía entre España y Eslovaquia y de la no pertenencia de este país a Europa Oriental, lo que debería significar su rechazo del comunismo.

A principios de los años 60, Cieker publicó varios textos muy similares a los ya analizados, sobre todo desde el punto de vista temático e ideológico. El artículo "El legado perenne de los santos Cirilo y Metodio (863-1963)" (Cieker, 1963a: 217-222) conmemora el 1100 aniversario de la llegada de estos apóstoles a Gran Moravia y su obra religioso-cultural; el estudio "El análisis de un mito: Ficciones y realidades del estado checo-eslovaco" (Cieker, 1963b: 113-133) ofrece una vez más una visión crítica del estado checoslovaco y de sus políticos, con un resumen histórico de las relaciones entre ambas naciones a partir del s. IX hasta los años 60, describiendo a su vez Checoslovaquia como un estado que vivía en una contradicción entre su principio creador y la práctica del mismo y que, consecuentemente, tenía que desaparecer. El estudio "Reflexiones sobre Europa" (Cieker, 1962: 169-185) destaca por su anticomunismo, su orientación hacia la juventud europea y puede interpretarse como una apelación para la unión de toda Europa bajo la idea cristiana. Sin embargo, con respecto a la posición de Cieker como líder del exilio eslovaco en España, parece más relevante el artículo "La causa común cristiana". Su primera parte lleva el nombre de "Eslovaquia y España" y el autor describe aquí la postura de los eslovacos frente a la Guerra Civil Española, opuesta a la del gobierno checoslovaco, que según Cieker enviaba armas y dinero a las "huestes de Kremlin" (Cieker, 1960: 77). El autor alega que por otro lado, "nosotros católicos eslovacos [...] nos hemos puesto abierta y conscientemente al lado de nuestros hermanos en la Fe, porque sabíamos [...] que en España por vez primera se planteaba con proyección universal el destino de Europa [...]" (ibídem: 78). Alarma sobre el peligro del comunismo universal, siendo Eslovaquia una de sus víctimas y destaca el papel de España, vencedora del comunismo, que fue capaz de cumplir su misión nacional y universal. Vuelve una vez más al tema de la guerra española alegando: "Dios dio la victoria a los que permanecieron fieles a Él y a la patria. Porque si esta victoria, cuyo artífice fue el Caudillo, no hubiera traído nada más que esta paz cristiana que disfrutáis, os habría dado todo" (ibídem: 78-79). Termina 
poniendo en contraste el comunismo, el verdadero vencedor en la Segunda Guerra Mundial; y la fe cristiana y católica, ya que "sin la Cruz auténtica y sin el amor cristiano, no se puede luchar contra la realidad comunista y menos aún vencerla” (ibídem: 88). Ahora bien, temática e ideológicamente Cieker se mantiene fiel a su visión anticomunista y profundamente católica, interpretando la historia nacional como una misión anticomunista o como una cruzada. Una vez más menciona el tema de la Eslovaquia sufriente, ahora bajo el yugo comunista. Sin embargo, en este caso alaba a España y a su Caudillo, destacando a su vez las simpatías de los eslovacos con los franquistas ya durante la Guerra Civil. La razón de su postura positiva frente a Franco debe ser su gratitud por otorgar asilo a la emigración eslovaca. Esta hipótesis viene demostrada por su ensayo "Al margen de un aniversario" en el que agradece la ayuda española ofrecida a los universitarios mediante la creación del CMSA (Cieker, 1950: 71 73). Por otro lado, sus acusaciones al gobierno checoslovaco sobre los envíos de armas para los republicanos son falsas, ya que Checoslovaquia se adhirió ya en agosto de 1936 al "Pacto de No Intervención".

Si los miembros del exilio checo en España criticaban a Cieker, en las memorias de los estudiantes eslovacos del CMSA viene descrito de manera positiva, alabando sus actividades a favor de la independencia eslovaca (Chajma, 1998; Kolmajer, 1998a: 354356). Uno de los estudiantes, Karol Belák, lo describe como "el pilar espiritual de un colegio internacional" (Belák, 1999: 10). En este sentido hay que mencionar que el grupo de los exiliados eslovacos podía, gracias a los contactos políticos de Cieker, desarrollar en Madrid una notable actividad: la conmemoración anual del día de la declaración del Estado eslovaco (14 de marzo), las visitas de personajes destacados del exilio eslovaco en España o las manifestaciones a favor de la Iglesia del silencio en Madrid en los años 50. Otra de las actividades de Cieker, la organización de la emisión eslovaca en la Radio Nacional de España (RNE), es la muestra más evidente de los conflictos entre el exilio eslovaco y checo en la España franquista. La emisión en las lenguas extranjeras en la RNE empezó en 1949 con el objetivo propagandístico en los países del Bloque soviético (Eiroa, 2018: 9-11). Kolmajer recuerda (1998a: 352-355) que la emisión eslovaca empezó el día 1 de octubre de 1949, al principio con programas de 15 minutos y 3 días por semana, más tarde con una emisión diaria que duraba 30 minutos y por la que los dos empleados eslovacos (Cieker, Kolmajer) recibían cada uno 896 pesetas mensuales. Esta emisión reconocía la continuidad de la soberanía eslovaca y al igual que las demás emisiones en las lenguas extranjeras, no se subordinaba a la censura franquista. El programa contenía entrevistas con varios exiliados eslovacos, así como temas políticos, culturales o deportivos (Vontorčík, 2013: 70-72). La emisión en checo, que empezó dos años más tarde, tenía al principio como locutores a los estudiantes eslovacos: Michal Ševc, Jozef Šiky y Boris Gašpar (Kolmajer, 1998a: 354). Para subrayar la conflictividad entre los exiliados cabe destacar que Formánek, como miembro del Consejo de Checoslovaquia Libre (una de las organizaciones del exilio checoslovaco), no reconocía la legitimidad de esta radioemisión checa (Vurm, 2007: 56). 
De Gottwald a Franco: el exilio checo y eslovaco en la España franquista

Uno de los discípulos más activos de Cieker en el exilio fue Štefan Glejdura ${ }^{5}$. Como inválido de guerra logró huir de Checoslovaquia y tras su estancia en Alemania y estudios en Bélgica llegó al CMSA en 1954 (Belák, 1999: 113-115; Mihalovič, 2003: 87). Al finalizar los estudios, trabajó durante la mitad de los años 60 en el Ministerio de Información y Turismo y más tarde se convirtió en profesor en la universidad madrileña, así como en el redactor de la Revista de Política Internacional, siendo a su vez uno de sus más activos autores. Glejdura publicaba en esta revista una serie de artículos orientados hacia los países de Europa Oriental ("Los grandes problemas del Este europeo"). El primero de ellos se publicó en 1968 bajo el título "Los grandes problemas del Este europeo: Eslovaquia".

En este artículo analiza la situación actual en Checoslovaquia con un enfoque especial en la posición eslovaca dentro de ella. Uno de los asuntos principales estudiados aquí es la cuestión de la federalización del estado checoslovaco y las relaciones entre los checos y los eslovacos. El autor alega que "la idea de un Estado federal de checos y eslovacos salió de entre los eslovacos de hace más de cincuenta años [...] y no era obra de los comunistas. Esta idea está profundamente arraigada en la nación eslovaca [...]" (Glejdura, 1968a: 19). A su vez añade, que la situación eslovaca es muy complicada por encontrarse entre sus dos principales enemigos - la URSS y los Países checos. Sin embargo, los checos van a aceptar la federalización de Checoslovaquia (ibídem: 20). Glejdura dice que "Masaryk y Beneš transformaron a Checo-Eslovaquia en Checoslovaquia sin el consentimiento de las potencias aliadas o de los eslovacos [...] para someter a su régimen centralista a Eslovaquia y asimilar por completo a su población" (ibídem: 35-36). Continúa con la crítica de los representantes checoslovacos, describiendo a Beneš como el "hombrecito checo al servicio de la masonería internacional", responsable de la muerte del presidente del Estado eslovaco Jozef Tiso (ibídem: 38,40). Se puede ver que la interpretación de Glejdura sobre el Estado eslovaco es plenamente positiva. La definición de este estado como fascista fue, según él, resultado de la propaganda checa y la declaración de la independencia eslovaca, "no podía depender de un arreglo personal entre Tiso e Hitler, sino de la decisión que fuera tomada por los representantes legales del país" (ibídem: 44-45, 48). La ocupación del resto de Checoslovaquia por el Tercer Reich en este sentido queda calificada por el autor como el resultado de la "democracia checa" (ibídem: 48). Glejdura termina su estudio con una mirada hacia los comunistas eslovacos que en el año 1939 aceptaron la independencia de Eslovaquia, viendo una semejanza entre los comunistas eslovacos de los 30 y de los 60. Lo que sorprende en este estudio es la ausencia de una crítica hacia los comunistas eslovacos: Glejdura elogia sus proyectos de

5 Štefan Glejdura (1925-1988) huyó de Checoslovaquia en noviembre de 1949 junto con K. Belák. La razón de su salida fue el descontento con la situación en la Facultad de Derecho, asî como con los cambios políticos y sociales tras el Golpe de Praga. Belák añade (1999: 114) que Glejdura formó parte del Levantamiento Nacional Eslovaco, sin embargo, no se sabía en qué bando luchaba. 
federalización, interpretando erróneamente estos intentos como la afirmación del deseo independentista de los eslovacos. Hay que añadir que el objetivo de la federalización fue, obviamente, la equiparación y soberanía de las dos naciones. Sin embargo, los verdaderos intentos independentistas no aparecen hasta los años 90, siendo la voluntad de los eslovacos por su independencia más bien el deseo de los representantes del exilio eslovaco que la realidad contemporánea eslovaca.

Su siguiente artículo, denominado "Los grandes problemas del Este europeo: Checoslovaquia", se publicó un mes después de la invasión de Checoslovaquia por el Pacto de Varsovia. Sin embargo, su temática y contenido ideológico son muy parecidos al previo artículo: federalización de Checoslovaquia, los intentos de liberalización del régimen por los comunistas eslovacos, crítica del concepto de checoslovaquismo y de los representantes políticos de la Primera República Checoslovaca. Por otro lado, Glejdura aquí analiza también el camino hacia la ocupación de 1968: describe la postura de otros países del bloque oriental frente a la Primavera de Praga, las negociaciones entre los comunistas sobre la situación de Checoslovaquia e incluso la propia invasión (Glejdura, 1968b: 18-28). Esta fue según su opinión un "grave error", ya que en el país no había ningún peligro de invasión por los países capitalistas y dice que, en contraste con la sublevación en Hungría en 1956, esta invasión no tiene ninguna justificación legal, ya que en Checoslovaquia no hubo rebelión, solo intentos de liberalización y de arreglo de las relaciones checo-eslovacas (ibídem: 29-30). Añade que la ocupación ayudó a los checos y eslovacos a superar sus problemas nacionales y a unirse en la resistencia pasiva. Termina con la afirmación de que "es preferible que Eslovaquia siga conviviendo por algún tiempo con los checos a ser incorporada a la URSS, mediante una proclamación de independencia del país [...]" (ibídem: 30, 33). Ahora bien, su interpretación de la invasión de 1968 parece ser objetiva: de verdad no hubo ninguna sublevación en Checoslovaquia, tan solo unos esfuerzos de democratización del régimen, situación muy distinta de la Revolución húngara de 1956. A su vez, los 137 ciudadanos checoslovacos muertos a causa de la invasión en el año 1968 (Pejčoch Tomek, 2017: 267, 287), así como las protestas de checos y eslovacos contra la ocupación (incluso en forma de autoinmolación) demuestran que los acontecimientos de 1968 de verdad silenciaron los problemas nacionales.

Otros estudios de Glejdura vinculados con el problema checo-eslovaco se dedicaron una vez más a la cuestión de la federalización de Checoslovaquia (Glejdura, 1970), a las relaciones entre Eslovaquia y la URSS (Glejdura, 1971) o a la conmemoración de los treinta años desde el Levantamiento Nacional Eslovaco y del Levantamiento anti-invasión de 1968 (Glejdura, 1974). En el artículo "Checoslovaquia: cinco años después" Glejdura describe la situación actual en Checoslovaquia transcurridos cinco años desde la invasión, interpretando la crisis de los años 1968-69 no solo como un intento de democratización de la sociedad y como una crisis del comunismo, sino también como un problema de las relaciones checo-eslovacas y de la federalización (Glejdura, 1973: 96). El estudio "Eslovaquia, en erupción revolucionaria 
De Gottwald a Franco: el exilio checo y eslovaco en la España franquista

(1945-1975)" analiza el desarrollo político-histórico del país durante los 30 años que han pasado desde el fin de la guerra. La incorporación de Eslovaquia al estado checoslovaco en 1945 fue según su interpretación solo una decisión de los Aliados y una "violación del derecho de autodeterminación", mientras que la derrota de los comunistas en las elecciones de 1946 en Eslovaquia tuvo como consecuencia su rechazo a la independencia eslovaca (Glejdura, 1976: 119-120). Este artículo está dedicado también a la posición de la Iglesia católica después del Golpe de Praga, alegando que "no se trataba tan solo de restringir la libertad religiosa desde el primer momento de la restauración de Checoslovaquia por el régimen frente-populista, sino también de la paralización directa de la religión mediante medidas administrativas, policíacas y judiciales" (ibídem: 123). En cuanto a la época de las purgas de 1950 en Eslovaquia, se enfoca en el problema de la persecución del clero y de los procesos contra los "nacionalistas burgueses" de origen eslovaco (ibídem: 127-129). Glejdura aquí erróneamente afirma que la opresión antirreligiosa del régimen fue más dura en Eslovaquia que en el territorio checo, por ser la mayoría de los eslovacos católicos, identificando así la lucha antirreligiosa con el combate contra los católicos. Ahora bien, la persecución de la Iglesia católica por el régimen comunista es un asunto bien conocido, siendo el proceso contra los tres obispos eslovacos de 1951 uno de los más infames. Sin embargo, esta opresión tuvo lugar también en el territorio checo y se orientó, en distintas intensidades, también contra varias confesiones cristianas.

Cabe añadir que Glejdura se convirtió, tras la muerte de Cieker en enero de 1969, en el director de la emisión eslovaca de RNE y también en el líder del exilio eslovaco en Madrid, sin embargo, su actividad fue limitada al entorno publicitario y universitario (Chajma, 1998: 143). El puesto del representante de los intereses eslovacos en España se quedó así desocupado, la razón no fue solamente la muerte del último enviado oficial eslovaco, sino también el cambio en la situación internacional: la España franquista en la búsqueda de nuevos mercados decidió fortalecer las relaciones con los países del Bloque del Este. En el caso de Checoslovaquia, en 1964 la delegación de empresas checoslovacas del comercio exterior se abrió en Madrid y en 1971 el acuerdo consular y comercial entre los dos países se firmó (Vurm, 2007: 69).

La ya mencionada emisión checa de RNE, que empezó más tarde que la eslovaca, fue dirigida por otra organización del exilio, el Comité Nacional Checo (Kolmajer, 1998a: 354). Como recuerda uno de los locutores de esta emisión, el estudiante eslovaco Boris Gašpar, el historiador y el representante de dicho Comité, Bohdan Chudoba, visitó a Cieker en Madrid en 1955 y estuvo de acuerdo con un locutor eslovaco, ya que no tenía confianza en ninguno de los dos estudiantes checos en la CMSA (Gašpar, 2017: 193-194). Chudoba fue, aparte de Formánek, el representante más destacado del exilio checo en la España franquista, pero a diferencia de este, rechazaba el concepto de checoslovaquismo. Tras el Golpe de Praga decidió huir de 
Checoslovaquia, primero a Alemania y Francia, más tarde se exilió a los EE.UU. ${ }^{6}$ En la mitad de los años 50 empezó a colaborar con la redacción extranjera de la RNE, siendo el responsable por la radioemisión checa y viajando regularmente a España hasta el año 1964, cuando se asentó finalmente en Madrid. Su crítica sobre los políticos de Checoslovaquia (Beneš, Masaryk), sus conflictos con otros miembros del exilio checo, así como su orientación cristiana y tradicionalista tuvieron como consecuencia sus relaciones correctas con los representantes del exilio eslovaco, en contraste con Formánek (Blanco Sarto, 2018: 608-609). El interés de Chudoba por los Habsburgo y por la Edad Moderna queda demostrado en su libro "España y el Imperio", en el que analiza la política europea española en los s. XVI y XVII, con un enfoque especial en la influencia española en Bohemia con respecto a la Guerra de los Treinta Años. Ya en la introducción Chudoba alega que el propósito de este libro es "analizar la voluntad de España de dirigir y controlar la defensa de Europa y de la civilización cristiana" (Chudoba, 1963: 21). A pesar de una distancia temporal entre la época de los Habsburgo y la España del s. XX, ya el tema elegido insinúa la postura positiva del autor frente a la España de Franco. Como alega Putna (2005: 228) se sabe que Chudoba reconocía a Franco como un luchador contra el comunismo, a pesar de que criticaba su soporte del arte moderno. A su vez, demuestran esta hipótesis sus elogios a la España de los siglos XVI y XVII, a la España que combina "su orgullo nacional con su fe en una misión mesiánica” (Chudoba, 1963: 52), mientras que se podía ver una continuidad entre esta y la España de Franco. También el anticomunismo y el antinazismo de Chudoba son visibles mediante unas reflexiones sobre el mal de odio, que no puede dominarse de otra manera que por la lucha de vida o muerte; o en el párrafo dedicado a la intolerancia: "Tal vez nuestra propia generación, que ha conocido la herejía nazi, asî como la comunista, y ha tenido que instituir procedimientos legales contra ambas, estará en mejor disposición para comprender" (ibídem: 57, 152). Su postura crítica hacia el comunismo está vinculada con la idea de la "política tradicional", opuesta a la "política natural" (despotismo ilustrado); mientras que aclara que por esta razón y "después de casi tres siglos, estamos de nuevo mejor predispuestos a comprender que una «política tradicional», política basada en una serie de principios morales [...] puede ser tan eficaz para preservar la libertad espiritual [...]" (ibídem: 36-37). El autor también interconecta el tradicionalismo con el nacionalismo, denominando a la España de los Austrias como la base de la defensa de las tradiciones europeas (ibídem: 52).

Su artículo "El pasado histórico y su sentido" demuestra su interés por los temas filosóficos y teológicos, lo que puede concebirse como una reflexión filosófico-histórica sobre los conceptos de historia, memoria, libertad y esperanza, dirigiéndose todos siempre hacia Dios, ya que el centro de la historia es la persona de Cristo y "el único

\footnotetext{
${ }^{6}$ Bohdan Chudoba (1909-1982) escapó de Checoslovaquia en febrero de 1948 y cruzó la frontera esquiando. A pesar de ser diputado del Partido Popular Checoslovaco, en 1946 fue detenido por su crítica a los comunistas y tras el Golpe de Praga correctamente presumía sus futuros problemas en el caso de quedarse en Checoslovaquia.
} 
«progreso» que podemos concebir de modo realista es el de cada persona por separado hacia la última verdad y la última libertad, que es Dios" (Chudoba, 1964: 32, 37). El tema histórico y a su vez religioso aparece también en el libro "Los tiempos antiguos y la venida de Cristo" dedicado a la Historia Antigua, pero siempre concentrado en Cristo, "el hombre más perfecto, porque era Dios y en las obras con que expió los hechos acontecidos antes de su venida, en su tiempo, y más tarde, consumido en el vértice encarnado de la historia" (Chudoba, 1965: 9-10). Este libro puede encuadrarse dentro de la teología histórica, reconociendo a Cristo como el apogeo de la historia, mientras que el autor alega que "cronológicamente, sin embargo, la vida de Cristo está muy cercana a nosotros" (ibídem: 10). Chudoba aquí presenta la interpretación de la historia, en la que la fe se convierte en el camino del conocimiento y a su vez busca el sentido de la historia, cuyo centro es Cristo (Blanco Sarto, 2018: 617, 620). No se pueden encontrar aquí muchas pruebas de su inclinación ideológica pro-franquista, quizá la única es la designación de Carlomagno como "caudillo" (Chudoba, 1965: 248). Estamos de acuerdo con la afirmación de Blanco Sarto (2018: 622), "el pensamiento de Chudoba supera a todo el positivismo, determinismo y evolucionismo, su base está formada por los principios cristianos de la libertad y de la esperanza, que son claves para la historia, el presente y el futuro".

\section{Conclusiones}

Al analizar los textos de Glejdura, es posible observar la ausencia del elemento católico y a su vez, su anticomunismo está orientado casi exclusivamente contra los comunistas checos y soviéticos. Teniendo en cuenta que se trata de un exalumno de Cieker y miembro del exilio eslovaco, no nos sorprende su orientación temática (las relaciones checo-eslovacas), tampoco su nacionalismo ni la visión crítica de los políticos de Checoslovaquia. A su vez, el papel del problema de las relaciones checo-eslovacas dentro de la situación internacional parece ser exagerado y puede concebirse como un instrumento utilizado por los exiliados para subrayar el carácter nacionalista y separatista de los eslovacos. En los textos de Chudoba se puede ver el elemento anticomunista, por otro lado, el componente nacionalista está marginalizado y en vez del catolicismo se acentúa la cristiandad. En el caso de Chudoba hay que destacar también el problema de su distanciamiento con España (al menos hasta la mitad de los años 60). A su vez, hay que tener en cuenta que la publicación de los textos de Glejdura tuvo lugar a finales de los 60, una época muy distinta en cuanto a la política exterior de la España franquista. Por otro lado, en los estudios de Cieker es visible su fuerte anticomunismo, un énfasis en el catolicismo, la crítica de la modernidad, las ideas de reconquista (mediante una cruzada) e incluso una existencia consustancial de catolicismo (cristiandad) y patria. En conclusión, en los textos de los tres exiliados se puede encontrar un rasgo común - el anticomunismo, a pesar de que cada uno de los autores interpretó este término de una manera distinta. Además, la ausencia del 
concepto del checoslovaquismo y de la fe en la restauración de la Checoslovaquia democrática es la conexión ideológica que hizo posible la convivencia entre Chudoba y los separatistas eslovacos (en contraste con la mayoría de los exiliados checos encabezados por Formánek) en el exilio en la España de Franco.

\section{Referencias bibliográficas}

Archivo General de Administración (AGA), fondo Ministerio de Asuntos Exteriores (MAE), caja 82/11623, legajo R.4435/21, no. 301/54. Anexo "Exiliados y residentes checoslovacos en España” a la carta de Zdenko Formánek a Daniel Castell Marco, 8.6.1954.

AGA, f. MAE, c. 82/11623, 1. R.4435/21, no. 301/54. Anexo "Carta de Antonin Blaha a José M. Otero Navascués, 14.5.1954” a la carta de Zdenko Formánek a Daniel Castell Marco, 8.6.1954.

AGA, f. MAE, c. 82/9309, 1. R.3358/18: Extranjeros en España - Vigilancia Checoslovaquia. Carta de Zdenko Formánek a Mariano de Iturralde, 16.3.1953.

Archivo de Servicios de Seguridad (Archiv bezpečnostních složek) (ABS), f. Studijní ústav MV (Instituto de Estudio del Ministerio de Interior) (SÚ MV), sign. Z-10-651-14, 7-8.

ABS, f. SÚ MV/2M, sign. 12824, no. 03214/48. Emigración eslovaca - informaciones, 14.1.1948.

Archivo del Ministerio de Asuntos Exteriores de la República Checa (Archiv MZV) (AMZV), f. Teritoriální odbory - tajné (Sección territorial - reservado) (TO - T): Španělsko (España) 1945-54, c. 1, carp. 057/151: España: asuntos diplomáticos misión diplomática checoslovaca en Madrid, no. 43779/V-1/48. Nota de Jozef Cieker, 19.12.1945.

AMZV, f. TO - T: España 1945-54, c. 1, carp. 057/151, no. 43779/V-1/48. Nota del MAE en Praga para el Comisionado de Finanzas en Bratislava, 21.6.1948.

AMZV, f. Osobní spisy (Expedientes personales), carp. Dr. Cieker Jozef, no. 25/res./46. Carta del primer secretario P. Cablk, citada en el informe de la Embajada checoslovaca en París para MAE en Praga, 31.1.1946.

AMZV, f. Expedientes personales, carp. Dr. Cieker Jozef, no. 143/46. Informe de Z. Formánek para el MAE en Praga, 15.1.1946.

AMZV, f. Expedientes personales, carp. Dr. Cieker Jozef, no. 391/48, Sentencia del Tribunal popular en Bratislava contra Dr. Jozef Cieker, 28.5.1948.

Bartlová, Alena (2000). Dr. Jozef Cieker, vel’vyslanec Slovenskej republiky (koreferát). En: Chovan-Rehák, Juraj (ed.). Dr. Jozef Cieker. Seminár pri príležitosti nedožitých 90. narodenín Jozefa Ciekra v Turdošine 20. júna 1997 (2000), Martin: Matica slovenská. 57-69. 
De Gottwald a Franco: el exilio checo y eslovaco en la España franquista

Belák, Karol (1999). Madrid: Zastávka a križovatka slovenského študenta (1951-1960). Nitra: Agroinštitút.

Blanco Sarto, Pablo (2018). Bohdan Chudoba (1909-1982). Teologické pojetí dějin. En: Chudoba, Bohdan. Clověke nad dějinami (2018), Praha: Torst. 608-622.

Chajma, František (1998). Slovenský post v Madride. En: Chovan, Juraj - Grácová, Genovéva - Maruniak, Peter (eds.). Slovenský povojnový exil: Zbornik materiálov zo seminára Dejiny slovenského exilu po roku 1945 v Matici slovenskej v Martine 27.-28. júna 1996 (1998), Martin: Matica slovenská. 143-147.

Chudoba, Bohdan (1965). Los tiempos antiguos y la venida de Cristo, Madrid: Rialp.

Chudoba, Bohdan (1964). El pasado histórico y su sentido. Atlantida: Revista del pensamiento actual, 7. 29-40.

Chudoba, Bohdan (1963). España y el Imperio (1519-1643). Madrid: Rialp.

Cieker, Jozef (1963a). El legado perenne de los santos Cirilo y Metodio (863-1963). ReUnión, 36. 217-222.

Cieker, Jozef (1963b). El análisis de un mito: Ficciones y realidades del estado checoeslovaco. Oriente Europeo, 13. 113-133.

Cieker, Jozef (1962). Reflexiones sobre Europa. Oriente Europeo, 12. 169-185.

Cieker, Jozef (1960). La causa común cristiana. Oriente Europeo, 1-2. 77-88.

Cieker, Jozef (1954). La lucha por el espacio centroeuropeo. Oriente, 3. 169-188.

Cieker, Jozef (1953). La lucha por el espacio centroeuropeo. Oriente, 4. 281-292.

Cieker, Jozef (1952a). La lucha por el espacio centroeuropeo. Oriente, 3. 147-158.

Cieker, Jozef (1952b). La lucha por el espacio centroeuropeo. Oriente, 4. 213-230.

Cieker, Jozef (1951). La entrada de los eslovacos en la comunidad cristiana. Oriente, 2. 61-74.

Cieker, Jozef (1950). Al margen de un aniversario. Nosotros: Boletín del Colegio Mayor Santiago Apóstol, 4-5. 71-73.

Eiroa, Matilde (2018). From The Iron Curtain to Franco's Spain: Right-Wing Central Europeans in Exile. Central Europe, 1. 1-16.

Eiroa, Matilde (2005). Pax Romana y los estudiantes católicos del este de Europa. Solidaridad y perspectivas de futuro. En: Sánchez Recio, Glicerio (ed.). La Internacional Católica. Pax Romana en la política europea de posguerra (2005), Madrid: Biblioteca Nueva. 257-301.

Gašpar, Boris (2017). Z ostravských bani do austrálskeho vel'komesta. Martin: Matica slovenská. Glejdura, Štefan (1976). Eslovaquia, en erupción revolucionaria (1945-1975). Revista de Politica Internacional, 143. 115-137. 
Maroš Timko

Glejdura, Štefan (1974). Aniversarios olvidados: treinta años del "Levantamiento Nacional Eslovaco", de 1944, y el "Levantamiento Antiinvasión", de 1968. Revista de Politica Internacional, 135. 235-244.

Glejdura, Štefan (1973). Checoslovaquia: cinco años después. Revista de Política Internacional, 127. 95-110.

Glejdura, Štefan (1971). Los grandes problemas del Este europeo: las relaciones sovieto-eslovacas. Revista de Politica Internacional, 116. 63-72.

Glejdura, Štefan (1970). La Ley constitucional sobre la Federación checo-eslovaca. Revista de Política Internacional, 111. 179-185.

Glejdura, Štefan (1968a). Los grandes problemas del Este europeo: Eslovaquia. Revista de Política Internacional, 97. 9-56.

Glejdura, Štefan (1968b). Los grandes problemas del Este europeo: Checoslovaquia. Revista de Politica Internacional, 99. 11-33.

Kolmajer, Jozef M. (1998a). Slovenské vysielanie štátneho rozhlasu Radio Nacional de España. En: Chovan, Juraj - Grácová, Genovéva - Maruniak, Peter (eds.). Slovenský povojnový exil: Zbornik materiálov zo seminára Dejiny slovenskébo exilu po roku 1945 v Matici slovenskej v Martine 27.-28. júna 1996 (1998), Martin: Matica slovenská. 352-356.

Kolmajer, Jozef M. (1998b). Vznik a poslanie Združenia slovenských katolíckych študentov v zahraničí. En: Chovan, Juraj - Grácová, Genovéva - Maruniak, Peter (eds.). Slovenský povojnový exil: Zbornik materiálov zo seminára Dejiny slovenskébo exilu po roku $1945 v$ Matici slovenskej v Martine 27.-28. júna 1996 (1998), Martin: Matica slovenská. 279-294.

Mihalovič, Viliam P. (2003). Oživené spomienky. Bratislava: Lúč.

Pejčoch, Ivo - Tomek, Prokop (2017). Okupace 1968 a její obéti: nové pobledy na invazi armád Varšavské smlouvy do Ceskoslovenska roku 1968, počátek okupace a její obèti. Praha: Vojenský historický ústav.

Putna, Martin C. (2005). "Summy“ a polemiky v rukopisném díle Bohdana Chudoby. Souvislosti, 3. 217-237.

Sayago, Sebastián (2014). El análisis del discurso como técnica de investigación cualitativa y cuantitativa en las ciencias sociales. Cinta de Moebio, 49. 1-10.

Smith, Tony (2000). New Bottles for New Wine: A Pericentric Framework for the Study of the Cold War. Diplomatic History, 4. 567-591.

Vontorčík, Emil (2013). Za krajanmi do Madridu alebo Vojna o Španielsko: Výbor cestopisných a historických eseji. Nitra: Sobor.

Vurm, Filip (2007). Ceskoslovensko-španèlské vątaby 1945-1975. Tesis de Máster. Praha: Universidad Carolina.

Westad, Odd Arne (2007). The Global Cold War: Third World Interventions and the Making of Our Times. Cambridge: Cambridge University Press. 